\title{
Karakteristik Morfometrik Keong Bakau (Telescopium telescopium) Di Ekosistem Mangrove Pantai Desa Daruba Kabupaten Pulau Morotai
}

\section{Morfometric Characteristics Of The Mangrove Snail (Telescopium telescopium) In The Mangrove Ecosystem Of Daruba Beach Village, Morotai Island District}

\author{
Julfikar Sibua $^{1}$, Nurafni ${ }^{1 *}$, Iswandi Wahab ${ }^{2}$, Kismanto Koroy ${ }^{1}$ \\ ${ }^{1}$ Program studi Ilmu Kelautan Fakultas Perikanan dan Ilmu Kelautan, Universitas Pasifik Morotai \\ ${ }^{2}$ Teknologi Hasil Perikanan Fakultas Perikanan dan Ilmu Kelautan, Universitas Pasifik Morotai \\ *Koresponden: nurafni1710@gmail.com
}

\begin{abstract}
ABSTRAK
Mangrove memiliki peranan sebagai siklus hidup biota moluska karena lingkungan mangrove menyediakan bahan makanan. Spesies Gastropoda yang berada diperairan desa Daruba Pantai adalah Telescopium telescopium dengan nama lokal (Bia papaco). Terjadinya pengurangan luasan mangrove akan berdampak pada kehidupan ataupun keberadaan Telescopium telescopium dari bentuk maupun panjang berat dari Telescopium telescopium sehingga perlu dilakukan penelitian morfometrik keong bakau (Telescopium telescopium). Penelitian ini dilaksanakan pada bulan Februari 2021 sampai Maret 2021 di desa Daruba Pantai, Kecamatan Morotai Selatan, Kabupaten Pulau Morotai. Metode yang digunakan adalah transek kuadrat dimana biota Telescopium telescopium diambil 5 kuadrat pada masing masing transek kuadrat secara acak. Hasil penelitian menunjukkan karakteristik Telescopium elescopium berbentuk kerucut pada ujung berbentuk melingkar, bagian luar cangkang dilengkapi garis spiral dan berwarna hitam kecoklatan sedangkan morfometrik Telescopium telecopium pada stasiun I sampai III memiliki panjang cangkang 4,51-5,95 cm, lebar cangkang dari stasiun I sampai III 2,11-2,54 cm dan berat cangkang 11,64-20,89 g sesuai dengan klasifikasi ukuran termasuk dalam kategori kecil.
\end{abstract}

Kata Kunci: Karakteristik, Morfometrik, Telescopium telescopium, Mangrove

\begin{abstract}
Mangroves have a role as a mollusca life cycle because the mangrove environment provides food. The gastropod species in the waters of Daruba Pantai village is Telescopium telescopium with the local name (Bia papaco). The reduction in mangrove area will have an impact on the life or existence of Telescopium telescopium from the shape and length of the weight of Telescopium telescopium so it is necessary to do morphometric research of mangrove snails (Telescopium telescopium). This research was conducted from February to March 2021 in the village of Daruba Pantai, South Morotai District, Morotai Island Regency. The method used is a quadratic transect where the Telescopium telescopium biota is taken at random 5 squares on each quadratic transect. The results showed the characteristics of Telescopium telescopium in the form of a cone at the end of a circular shape, the outer shell is equipped with a spiral line and brownish black in color, while the morphometric Telescopium telecopium at stations I to III has a shell length of 4.51-5.95 cm, shell width from stations I to station III. III $2.11-2.54 \mathrm{~cm}$ and shell weight $11.64-20.89 \mathrm{~g}$ according to the size classification included in the small category.
\end{abstract}

Keywords: characteristics, morphometric, Telescopium telescopium, mangrove

\section{PENDAHULUAN}

Ekosistem mangrove merupakan ekosistem yang mampu beradaptasi di daerah pasang surut dan memiliki fungsi fisik, biologi, ekonomi, dan ekologis. Ekosistem mangrove berperan sebagai penahan ombak, penetralisir pencemaran, perangkap sedimen, penahan intrusi air laut, pelindung garis pantai, tempat pemijahan, tempat asuhan, tempat mencari makan dan sebagai penunjang nutrien bagi biota-biota aquatik 
lainnya seperti hewan Moluska. Menurut Kurniawati et al., (2014) mangrove memiliki peranan sebagai siklus Moluska karena lingkungan mangrove menyediakan bahan makanan bagi organisme asosiasi salah satunya Gastropoda.

Spesies Gastropoda yang ditemukan di perairan desa Daruba pantai adalah jenis Telescopium telescopium atau Bia papaco dalam sebutan masyarakat lokal, sering ditemukan di kawasan mangrove. Telescopium telescopium hidup di ekosistem mangrove dan hampir ditemukan pada substrat berlumpur dan dipengaruhi oleh pasang surut (Husein, et al., 2017). Air laut pasang, maka Telescopium telescopium membenamkan diri didalam lumpur. Mangrove yang alami dijadikan tempat hidup Telescopium telescopium dan biota lainnya sehingga rusak atau menurunnya ekosistem mangrove akan berdampak pada kehidupan biota asosiasinya.

Penelitian sebelum terdahuluAlwi et al., (2019) bahwa kondisi ekosistem mangrove di kawasan pesisir Desa Daruba Pantai semakin banyak mendapat tekanan baik fisik maupun ekologis seperti pembukaan lahan untuk pemukiman, penebangan pohon untuk kayu bakar dan bahan bangunan memberikan dampak yang signifikan terhadap kelangsungan hidup mangrove. Terjadinya pengurangan luasan mangrove akan berdampak pada kehidupan ataupun keberadaan Telescopium telescopium dari bentuk maupun panjang berat dari Telescopium telescopium sehingga perlu dilakukan penelitian morfometrik dan kepadatan keong bakau (Telescopium telescopium).

Morfometrik merupakan studi yang berkaitan dengan variasi dan perubahan bentuk (ukuran dan bentuk) dari organisme, meliputi pengukuran panjang berat dan analisis kerangka suatu organisme (Arfah, 2018). Pengukuran morfometrik gastropoda ditentukan berdasarkan ukuran panjang dan lebar cangkang yang ditemukan.

\section{METODE PENELITIAN}

Penelitian ini dilaksanakan pada bulan Februari sampai Maret 2021 bertempat di Desa Daruba Pantai, Kecamatan Morotai Selatan, Kabupaten Pulau Morotai.

\section{Alat dan Bahan}

Bahan yang digunakan alkohol 70\%, air tawar dan Telescopium telescopium sedangkan alat yang digunakan adalah meteran roll, kuadrat $1 \times 1 \mathrm{~m}^{2}$, GPS, thermometer, handrefraktometer, indikator, $\mathrm{pH}$, plastik sampel, jangka sorong, kamera, timbangan digital dan alat tulis. 


\section{Prosedur Pengambilan Data}

Pengambilan sampel Telescopium telescopium dilakukan pada saat surut terendah. Sampel Telescopium telescopium yang berada diatas substrat dan yang menempel pada akar mangrove diambil kemudian dimasukan ke dalam plastik sampel yang telah diberi label, sampel kemudian dibersihkan dengan air mengalir sampai bersih dimasukkan ke botol plastik sampel yang telah berisi air dan Alkohol 70\%. Pengumpulan sampel Telescopium telescopium dengan menggunakan transek kuadrat yang ditarik dari arah laut kedarat sepanjang $50 \mathrm{~m}$ kemudian diletakan kuadrat berukuran 1x1 m secara acak (kuadrat diletakan dilokasi habitat keong bakau yang ditandai dengan kehadiran keong bakau).. Setiap transek kuadrat diambil 5 kuadrat secara acak untuk pengamatan populasi Telescopium telescopium. Sampel kemudian dibawa ke laboratorium FPIK untuk dilakukan pengukuran panjang,berat dan lebar (morfometrik) serta karakteristik (warna dan bentuk).

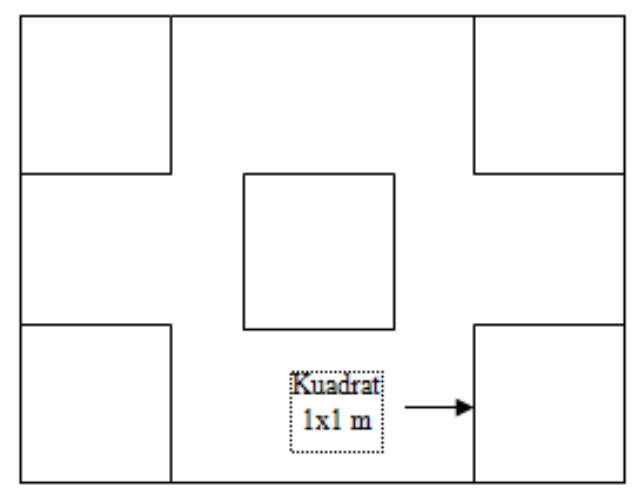

Gambar 1. Penempatan transek kuadrat pengambilan sampelPengukuran parameter perairan diambil seperti suhu air, $\mathrm{pH}$ air, salinitas dan substrat secara in situ.

\section{Analisis Data}

Sampel Telescopium telescopium yang ditemukan kemudian dianalisis secara kuantitatif dan ditampilkan dalam bentuk tabel/gambar.

\section{HASIL DAN PEMBAHASAN}

\section{Parameter Lingkungan}

Hasil pengukuran parameter lingkungan sangat sesui untuk kehidupan gastropoda. menggambarkan setiap parameter lingkungan yaitu Suhu,salinitas dan $\mathrm{pH}$ pada tiga stasiun memiliki kisaran nilai bervariasi. Substrat dari menunjukan tidak ada perbedaan (Tabel 1). 
Tabel 1 . Parameter lingkungan di lokasi penelitian.

\begin{tabular}{cccc}
\hline Parameter & \multicolumn{3}{c}{ Stasiun } \\
& I & II & III \\
\hline Suhu $\left({ }^{\circ} \mathrm{C}\right)$ & 36 & 29 & 33 \\
Salinitas $(\%)$ & 30 & 25 & 25 \\
pH & 6,58 & 6,51 & 7,01 \\
Substrat & Berlumpur & Berlumpur & Berlumpur \\
\hline
\end{tabular}

Sumber: Data primer 2021

Kisaran suhu yang diperoleh masih dapat dikatakan kisaran normal untuk kehidupan gastropoda karena secara umum untuk gastropoda kisaran suhu yang ideal untuk pertumbuhan dan reproduksi gastropoda pada umumnya adalah $25-32{ }^{\circ} \mathrm{C}$ (Odum 1993). Menurut kurniawati et al., (2014) Kisaran normal suhu untuk keong bakau $28^{\circ}$ $36^{\circ} \mathrm{c}$ masih layak untuk biota laut.

Salinitas dapat mempengaruhi penyebaran organisme benthos baik secara horizontal maupun vertikal. Secara tidak langsung mengakibatkan adanya perubahan komposisi organisme dalam suatu ekosistem (Odum, 1993). Gastropoda yang bersifat mobile mempunyai kemampuan untuk bergerak guna menghindari salinitas yang terlalu rendah. Kisaran salinitas yang optimal untuk kehidupan Gastropoda berada pada kisaran 28-34. Effendi (2003) menjelaskan bahwa adanya kenaikan dan penurunan salinitas dipengaruhi oleh penguapan, makin besar tingkat penguapan air laut di suatu wilayah.Menurut Marpaung (2013) untuk dapat hidup normal hewan benthos harus berada pada rentang salinitas antara 25-34 ppm.

\section{Derajat Keasaman (pH)}

Hasil pengukuran parameter $\mathrm{pH}$ dilokasi 6,51-7,01. Menurut Odum (1993), menyatakan gastropoda membutuhkan $\mathrm{pH}$ air kisaran 6,5-8,5 untuk kelangsungan hidup dan reproduksi. Menurut Effendi (2003) menyatakan sebagian besar biota akuatik sensitif terhadap perubahan $\mathrm{pH}$ dan menyukai nilai $\mathrm{pH}$ berkisar 7-8,5. Ramses et al.,(2018) menyatakan bahwa kisaran $\mathrm{pH}$ normal untuk moluska 6-8,4 .

\section{Substrat}

Peranan tekstur substrat dalam tanah memiliki korelasi yang kuat terhadap ketersediaan bahan organik yang terkandung dalam sedimen dan oksigen. Hal ini dijelaskan dalam Bengen (2001) bahwa jenis substrat mengandung pasir akan sedikit 
jumlah organisme dan nutrient di dalamnya karena partikel sedimen yang kecil akan menghanyutkan nutrient, dan apabila substrat halus biasanya nutrient yang terkandung didalamnya cukup besar. Riniatsih (2009) menjelaskan bahwa semakin halus tekstur substrat maka semakin banyak kandungan unsur hara. Romdhani (2016). menjelaskan bahwa substrat berlumpur kaya akan bahan organik. Sihombing et al (2013) menjelaskan bahwa tingginya kandungan lumpur dapat mendukung kehidupan gastropoda karena fraksi yang lebih halus akan mengakulasi bahan organik yang jauh lebih besar daripada sedimen yang cenderung substrat kasar.

\section{Karakteristik dan Morfometrik}

Ukuran dan bentuk tubuh kerucut individu Telescopium telescopium Keong bakau yang digunakan memiliki tubuh simetris bilateral dengan cangkang yang kuat, berbentuk kerucut pada ujung dan melingkar. Lapisan luar cangkang keong bakau dilengkapi garis spiral yang sangat rapat serta jalur yang melengkung ke dalam,Telescopium telescopium memiliki warna cangkang dalam coklat keruh, coklat keunguuan dan coklat kehitaman. Ukuran tubuh memperlihatkan perbedaan antara stasiun I, II sampai III. Telescopium telescopium yang berukuran kecil merupakan ukuran yang paling banyak ditemukan pada semua lokasi penelitian (Tabel 2). Hal ini disebabkan pengaruh dari tempat hidup dan penyedia habitat paling baik untuk mendukung kehidupan Telescopium telescopium, baik sebagai sumber makanan maupun habitat. Menurut Rahmawati et al., (2013) bahwa besarnya suatu organisme perairan dipengaruhi faktor makanan.

Tabel 2. Hasil Analisis Karakteristik dan Morfometrik.

\begin{tabular}{cccc}
\hline & & Stasiun & III \\
\hline Ukuran Tubuh & Rerata & II & Rerata \\
\cline { 2 - 4 } & 5.61 & 4.51 & 5.95 \\
SW & 2.54 & 2.11 & 2.37 \\
W & 20.89 & 11.64 & 16.9 \\
\hline Keterangan: SL $=$ Shell Length (Panjang Cangkang) & & \\
SW = Shell Width (Lebar cangkang) & & \\
W $=$ Weight (Berat Cangkang) &
\end{tabular}



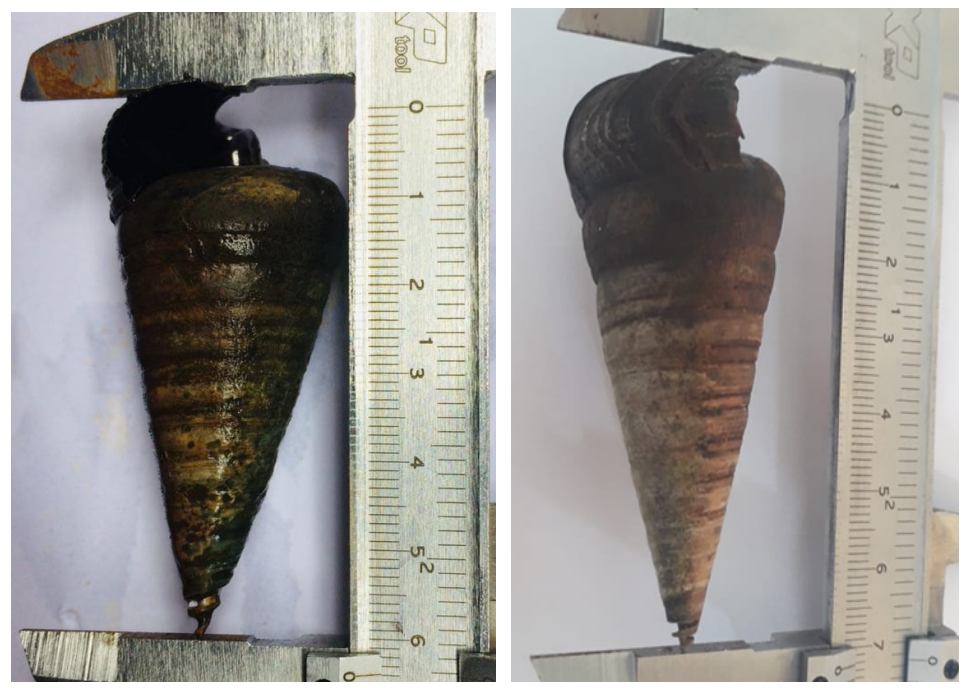

Gambar 2. Telescopium telescopium

Hasil perhitungan analisis karakteristik dan morfometrik pada stasiun I, II dan III mempunyai nilai yang berbeda-beda (Tabel 2). Panjang, lebar dan berat suatu cangkang. Akan tetapi berdasarkan kelas ukuran termasuk dalam kategori ukuran kecil $(4,70-6,53 \mathrm{~cm})$.

Tabel 3. Distribusi Telescopium telescopium berdasarkan kelas ukuran panjang total

\begin{tabular}{ccccc}
\hline Kelas Ukuran & Ukuran $(\mathrm{cm})$ & I & Stasiun & III \\
\hline Kecil & $4,70-6.53$ & 5.61 & 4.51 & 5.95 \\
Sedang & $6,54-8,96$ & 0 & 0 & 0 \\
Besar & $8.97-10,10$ & 0 & 0 & 0 \\
\hline
\end{tabular}

Hasil Klasifikasi berdasarkan ukuran panjang total dilokasi ukuran panjang total dilokasi berukuran 4,51 -5,95 cm yang tersebar di tiga stasiun dengan jumlah individu stasiun I (147 ind), stasiun II (96 ind) dan stasiun III (69). Sedangkan lebar cangkang 2,11 - 2, $54 \mathrm{~cm}$ dan berat cangkang berkisar 11,64 sampai $20.89 \mathrm{~g}$. Hubungan panjang berat merupakan faktor-faktor yang digunakan dalam penelitian biologi perikanan dalam menggambarkan perubahan ukuran individu, namun dapat juga digunakan untuk menunjukkan pola pertumbuhan dari suatu organisme (Gayon, 2000). Hubungan panjang berat perlu diketahui terutama untuk mengetahui pola pertumbuhan suatu organisme.

Pertumbuhan Telescopium telescopium berdasarkan panjang, lebar dan berat sangat bervariasi tergantung pada kondisi keong tersebut. Misalkan pada saat ditimbang terdapat banyak sekali air dalam cangkang, dengan demikian berat tubuh akan bertambah. Jadi untuk mempermudah dalam menduga panjang cangkang, diukur 
panjang kemudian mengkonversi kedalam berat atau sebaliknya. Keong bakau mengalami beberapa perbedaan bobot, panjang dan lebar karena pertumbuhan dari setiap keong yang berbeda-beda (Haslianti et.al 2017).

Menurut Eisler (2000) bahwa semakin besar ukuran berat dan morfometri Telescopium telescopium disebabkan tempat hidup yang masih dalam kateori baik, memiliki banyak makanan atau parameter yang mendukung keberadaan Telescopium telescopium. Begitu juga dengan meningkatnya salinitas, terbukti dari pengukuran parameter fisika kimia lingkungan (Tabel 1) terdapat perbedaan salinitas pada masingmasing stasiun pengamatan. Keberadaan dan penyebaran keduanya sangat dipengaruhi faktor abiotik dan biotik, seperti kondisi lingkungan, sumber makanan, pemangsaan dan kompetisi. Adanya tekanan dan perubahan lingkungan berpengaruh terhadap total famili dan perbedaan komposisi dari organisme. Keanekaragaman organisme tidak hanya menunjukkan jumlah jenis, tetapi juga mengetahui struktur, dan perbedaan komponen makro-mikro di habitat mereka. Menurut Kurniawan (2007), banyak atau tidaknya gastropoda di lokasi penelitian, dimungkinkan berhubungan dengan kondisi substrat atau tempat hidup dari masing-masing spesies. Keberadaan faktor makanan seperti detritus dan lingkungan juga sangat mendukung untuk kehidupan jenis-jenis gastropoda yang ditemukan.

Hal ini sesuai dengan pendapat penelitian dari Budiman (1991) yang mengemukakan Telescopium telescopium menyukai tempat lahan mangrove terbuka, genangan air yang cukup luas dan banyak terkena cahaya matahari. Berdasarkan hasil penelitian yang dilakukan oleh Rahmawati (2011) menyatakan bahwa kelimpahan keong telescopium di lahan masih bagus dan lebih besar dari pada kelimpahan Telescopium di mangrove yang sedikit dan diduga telescopium tidak memiliki daya adaptasi tinggi terhadap predator.

\section{KESIMPULAN}

Jenis Telescopium telecopium berbentuk kerucut, pada ujung berbentuk melingkar, bagian luar cangkang dilengkapi garis spiral dan berwarna hitam kecoklatan sedangkan morfometrik Telescopium telecopium pada stasiun I sampai III memiliki panjang cangkang 4,51-5,95 cm, lebar cangkang dari stasiun I sampai III 2,11-2,54 cm dan berat cangkang 11,64-20,89 g sesuai dengan klasifikasi ukuran termasuk dalam kategori kecil. 


\section{DAFTAR PUSTAKA}

Alwi D, Koroy K dan Laba E. 2019. Struktur Komunitas Ekosistem Mangrove di Desa Daruba Pantai Kabupaten Pulau Morotai. Jurnal Wahana Pendidikan Vol. 5, No.4.

Arfah N. 2018. Morfometrik Siput Sedot (Cerithidea cingulata) dan iput Pinang (Littoraria melanostoma) di Ekosistem Mangrove Pada Kawasan Industri dan Non Industri Kecamatan Sungai Sembilan Kota Dumai Provinsi Riau. Skripsi. Fakultas Perikanan dan Ilmu Kelautan. Universitas Riau.

Budiman A. 1991. Penelaahan beberapa gatra ekologi Moluska bakau Indonesia. Disertai. Sekolah Pascasarjana.UI. Jakarta.

Eiser, R.2000. Handbook of chemical risk assessment. First CRC Press LLC Printing. United States of Amerika.

Effendi H. 2003. Telaah kualitas air : bagi pengelolaan sumber daya dan lingkungan perairan. Kanisius. Yogyakarta

Gayon J. 2000. History of the concept all alometry. America Zoologist. 40 (5): 748-758.

Haslianti, In the M.G. Ishak E.2017. Karakteristik keong bakau Kowoe dan aktivitas antioksidannya. Jurnal Hasil Pengolahan Perikanan Indonesia. 20(1): 74-83.

Husein S, Bahtiar dan Oetama D. 2017. Studi kepadatan dan distribusi Keong Bakau (Telescopium telescopium) di perairan mangrove Kecamatan Kaledupa Kabupaten Wakatobi. Jurnal Manajemen Sumber Daya Perairan, 2(3): 235242.

Kurniawan. 2007. Fungsi dan Peranan Gastropoda di Ekosistem Mangrove. Fakultas Pasca Sarjana Universitas Indonesia.

Kurniawati A, Bengen DG, Maddupa H. 2014. Karakteristik Telescopium telescopium pada ekosistem mangrove di Segara Anakan, Kabupaten Cilacap, Jawa Tengah. Bonorowo. Wetlands. 4 (2): 71-81

Marpaung, Anggi Azmita, Fiqriyah. 2013. Keanekaragaman Makrozoobenthos di Ekosistem Mangrove Silvofishery dan Mangrove Alami Kawasan Ekowisata Pantai Boe Kecamatan Galesong Kabupaten Takalar.

Melda F.Aralaha, L. J. L. Lumingas dan Alex D. Kambey 2015. Kepadatan, Pola Sebaran dan Morfometrik Gastropoda (Telescopium telescopium) pada daerah Mangrove Jailolo Halmahera Barat Maluku Utara. Jurnal Ilmiah Platax. Vol. $3:(1)$.

Miller, J.B., James, J.K., dan Maggiore, P.M.A. 1993. Tables of composition of Australian aboriginal food. Aboriginal Studies Press: Canberra. p. 256.

Odum, E. P. 1993. Dasar Ekologi. Gadjah Mada Universitas Press. Yogyakarta.

Raharadian A, Prasetyo B.L, Setiawan Ydan Wikantika K.2019. Tinjauan Historis Data dan Informasi Luas Mangrove Indonesia. Media Konservasi. Vol. 24 No. 2. 
Rahmawati G, Fredinan Yulianda, Agustinus M. Samosir. 2013. Ekologi keong bakau (Telescopium telescopium, Linnaeus 1758) pada ekosistem mangrove Pantai Mayangan, Jawa Barat Bonorowo. Wetlands. 3 (1): 41-49, June 2013.

Ramses F, Yarsi E, dan Adil W. 2014. Kelimpahan populasi dan perbedaan morfometri Telescopium telescopium pada habitat Mangrove di sungai Bongkok Kampung Bagan Tanjung Piayu dan di sekitar TPA pinggir kota Batam. (1): $18-24$.

Ramses, Fauziah Syamsi, Notowinarto. 2018. Karakteristik Morfometrik, pola sebaran, kepadatan dan kondisi lingkungan siput Gongong strombus canarium linnaeus, 1758 Di Perairan Kota Batam. Simbiosa, 7 (2): 95- 108.

Riniatsih, I dan Kushartono EW. 2009. Substrat Dasar dan Parameter Oseanografi sebagai penentu keberadaan Gastropoda dan Bivalvia di Pantai Sluke Kabupaten Rembang. Ilmu Kelautan. 14(1):50- 59.

Sihombing, B., Nasution Syafruddin dan Efriyeldi. 2013. Distribusi kelimpahan Gastropoda (Telescopium) di ekosistem mangrove muara Sungai Dumai. Sumatera 